GA-A22669

CONF-970758 -.

\title{
DESIGN OF THE FILL/TRANSFER STATION CRYOSTAT FOR THE OMEGA CRYOGENIC TARGET SYSTEM
}

\author{
by \\ C.R. GIBSON, C.M. CHARMIN, J.V. DEL BENE, E.H. HOFFMANN, \\ G.E. BESENBRUCH, and I. ANTEBY
}

\author{
RECEIVED \\ HoV 101993 \\ OSTI
}

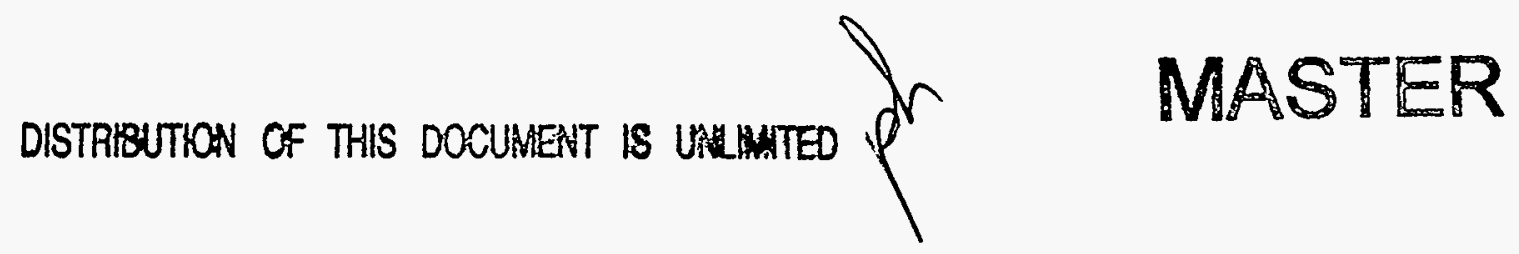




\section{DISCLAIMER}

This repor was prepared as an account of work sponsored by an agency of the United States Government. Neither the United States Government nor any agency thereof, nor any of their employees, makes any warranty, express or implied, or assumes any legal liability or responsibility for the accuracy, completeness, or usefulness of any information, apparatus, product, or process disciosed, or represents that its use would not infringe privately owned rights. Reference herein to any specific commercial produch, process, or service by trade name, trademark, inanufacturer, or otherwise does not necessarily constinute or imply its endorsement, recommendation, or favoring by the United States Governmeat or any ageacy thereor. The views and opinions of authors expressed herein do not aecessarily state or reflect those of the United States Government or any agency thereof. 


\section{DISCLAIMER}

Portions of this document may be illegible in electronic image products. Images are produced from the best available original document. 
GA-A22669

\title{
DESIGN OF THE FILL/TRANSFER STATION CRYOSTAT FOR THE OMEGA CRYOGENIC TARGET SYSTEM
}

\author{
by \\ C.R. GIBSON, C.M. CHARMIN, J.V. DEL BENE, E.H. HOFFMANN, \\ G.E. BESENBRUCH, and I. ANTEBY*
}

This is a preprint of a paper presented at the 1997 Cryogenic Engineering Conference (CEC) and International Cryogenic Materials Conference (ICMC), July 27 through August 1, 1997 in Portland, Oregon, and to be published in the Proceedings.

"University of Rochester, Laboratory for Laser Energetics, Rochester, New York. Permanent address: Nuclear Research Center, Negev, Israel.

\author{
Work supported by \\ the U.S. Department of Energy under \\ Contract No. DE-AC03-95SF20732
}




\title{
DESIGN OF THE FILL/TRANSFER STATION CRYOSTAT FOR THE OMEGA CRYOGENIC TARGET SYSTEM
}

\author{
C. R. Gibson, ${ }^{1}$ C. M. Charmin, ${ }^{1}$ J. V. Del Bene, ${ }^{1}$ E. H. Hoffmann, ${ }^{1}$ \\ G. E. Besenbruch, ${ }^{1}$ and I. Anteby 2,3 \\ ${ }^{1}$ General Atomics \\ San Diego, California 92121, USA \\ ${ }^{2}$ University of Rochester, Laboratory for Laser Energetics \\ Rochester, New York 14623, USA \\ ${ }^{3}$ Permanent address: Nuclear Research Center, Negev, Israel
}

\begin{abstract}
General Atomics is designing, testing and fabricating a system for supplying cryogenic targets for the University of Rochester's OMEGA laser system. A prototype system has demonstrated the filling of $1 \mathrm{~mm}$ diameter, $3 \mu \mathrm{m}$ wall plastic spheres to $111 \mathrm{MPa}$ $(1100 \mathrm{~atm})$ with deuterium and then cooling to $18 \mathrm{~K}$ to condense the fuel. The production design must be capable of routinely filling and cooling targets with a 50/50 mix of deuterium and tritium and transferring them to a device which places the targets into the focus of 60 laser beams. This paper discusses the design and analysis of the production Fill/ Transfer Station cryostat. The cryostat has two major components, a fixed base and a removable dome. The joint between the base and the dome is similar to a bayonet fitting and is sealed by a room temperature elastomeric o-ring. Since the cryostat must be housed in a glovebox, its design is driven strongly by maintenance requirements. To reach the equipment inside the cryostat, the dome is simply unbolted and lifted. The inside of the cryostat is maintained at $16 \mathrm{~K}$ by a closed loop helium flow system. Gaseous helium at about 1.4 MPa (200 psi) flows through tubes which are brazed to the inner walls. Cooling is provided by several cryocoolers which are located external to the cryostat. Liquid nitrogen is used as a heat intercept and to precool the helium gas.
\end{abstract}

\section{INTRODUCTION}

As part of the national Inertial Confinement Fusion Program, General Atomics is designing, constructing and testing the OMEGA cryogenic target system. ${ }^{1}$ This system will be capable of filling, transporting, layering, characterizing, inserting, and positioning deuterium/tritium (DT) filled cryogenic targets. It will be part of the $30 \mathrm{~kJ}$ OMEGA laser at the University of Rochester's Laboratory for Laser Energetics in Rochester, New York. 
The fill/transfer station's requirements are to fill the targets with DT, cool them to cryogenic temperatures and transfer them to the next device for transport to the target chamber. The process begins when four mounted targets, assembled into a rack, are placed inside a high pressure permeation cell. The targets are filled with DT at pressures up to $152 \mathrm{MPa}(1500 \mathrm{~atm})$ and then are cooled to cryogenic temperatures to condense the DT. Using precision vacuum manipulators, one target is removed from the target rack and inserted onto the stalk of a moving cryostat. The moving cryostat then transports the target to the center of the OMEGA target chamber. It is positioned very accurately and then, after rapid removal of the thermal shroud, is shot by the lasers.

The mounted target, shown in Figure 1, includes a $1 \mathrm{~mm}$ diameter plastic sphere. This sphere is suspended from a beryllium "C" by three spider webs. This assembly is attached to the top of a boron post. The entire mount is about $20 \mathrm{~mm}$ tall.

\section{CRYOSTAT DESIGN}

As shown in Figure 2, the fill/transfer station consists of a large cryostat with several components attached. The inserter and target manipulator are precision vacuum manipulators for moving the targets. The permeation cell is a high pressure device capable of being uniformly cooled to $16 \mathrm{~K}$. The moving cryostat port contains several pieces of equipment needed to hand off the target from the fill/transfer station to the moving cryostat system.

\section{Cryostat}

The cryostat is of "belljar" design and consists of two distinct parts: a fixed base and a removable dome. The joint between the base and the dome is similar to a bayonet fitting and has a nominal $2.5 \mathrm{~mm}(0.10 \mathrm{in}$.) gap. This joint is sealed by a room temperature elastomeric o-ring at the joint between the base and dome. The cryostat is $1.25 \mathrm{~m}$ (49 in.) in diameter and $1.10 \mathrm{~m}$ (43 in.) high and is fabricated from 316 stainless steel.

Both the base and dome are vacuum insulated. These vacuum spaces are isolated to prevent tritium from contaminating the multilayer insulation (MLI). If this were to happen, it would be difficult to decontaminate the MLI due to its large surface area. The inner volume between the base and the dome operates with $6.6 \mathrm{~Pa}(50 \mathrm{mTorr})$ of helium. This gas removes heat from the target caused by decay of the DT.

The dome inner wall has an inside diameter of approximately $1.07 \mathrm{~m} \mathrm{(42} \mathrm{in.)} \mathrm{and} \mathrm{is} \mathrm{a}$ pressure boundary between the dome insulating vacuum and the inner volume. The inner
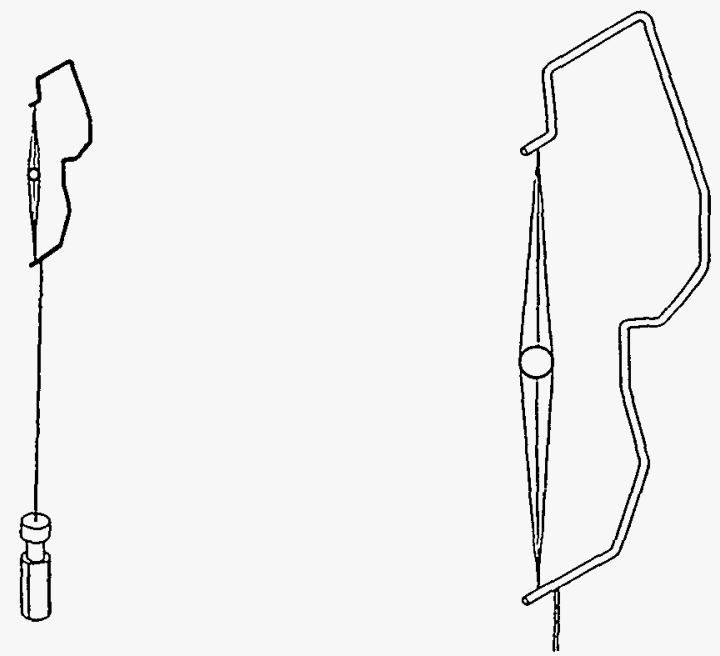

Figure 1. Sketch of mounted cryogenic target. Sketch on right is enlargement of beryllium "C", target sphere and spider webs. 

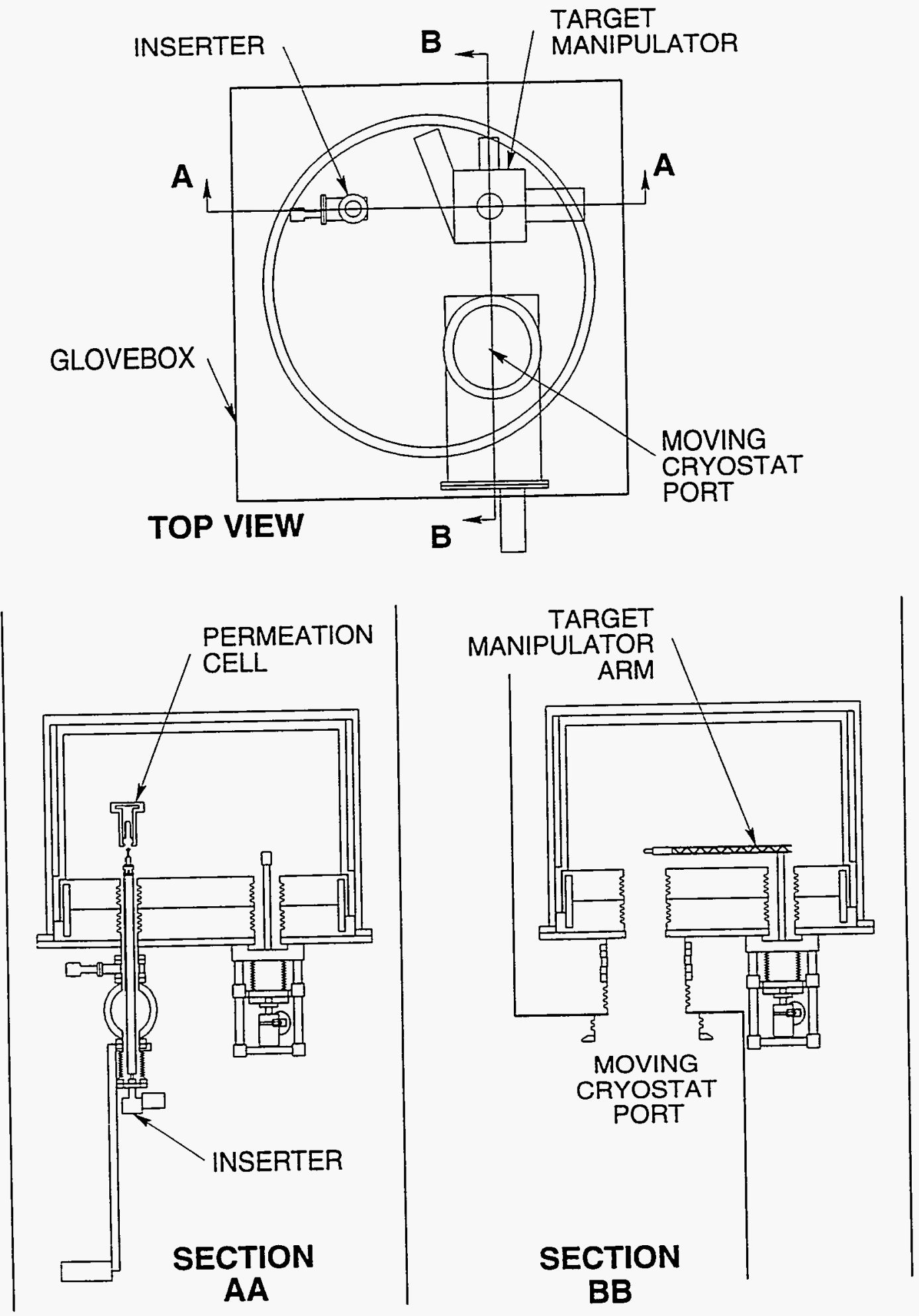

Figure 2. Sketch of Fill / Transfer Station showing cryostat, glovebox and major components.

wall has cooling tubes attached to it through which cold helium gas is circulated. This wall has a $16 \mathrm{~K}$ nominal temperature. Inside the insulating space, a liquid nitrogen cooled thermal shield is used to intercept both radiation heat transfer and conduction heat transfer coming up the mouth of the dome. 
The cryostat base is built around the $32 \mathrm{~mm}$ (1.25 in.) thick bottom plate. This plate supports the cryostat during operation and also supports the vacuum manipulators hanging below it. Between the bottom plate and the top plate is a vacuum insulating space which includes a liquid nitrogen cooled thermal shield and MLI. The penetrations between the two plates are sealed with metal bellows to insure that the base insulating space is isolated. The top plate of the base has cooling tubes attached to its bottom and has a nominal temperature of $16 \mathrm{~K}$. An elastomeric o-ring along the top edge of the base bottom plate is used to seal the base to the dome. A heating strip around the circumference of the bottom plate keeps the o-ring at room temperature.

For maintenance of equipment on the inside of the cryostat, the dome is simply unbolted and lifted vertically off the base. The lift mechanism is built into the glovebox. This design also allows warm alignment and checkout of all equipment, both outside and inside the cryostat.

\section{Cooling Module}

The cryostat cooling is provided by the cooling module which is located directly below the cryostat. The cooling module is designed around eight closed-cycle cryocoolers, Sumitomo SRD-210W, grouped into five independent helium circulation loops.

One loop is used to cool the permeation cell and another is dedicated to cool the moving cryostat thermal shroud. These two loops each have one cryocooler and are designed to be frequently cycled between room temperature and cryogenic temperatures. Flowing compressed helium gas at approximately $0.3 \mathrm{~g} / \mathrm{s}$ and $1.4 \mathrm{MPa}(200 \mathrm{psi}$ ) connects the components to be cooled with the liquid nitrogen bath and cryocoolers. It first flows through a liquid nitrogen bath to cool to approximately $80 \mathrm{~K}$. Next, it flows past the first stage of a cryocooler to bring it to about $50 \mathrm{~K}$, then past the second stage to drop its temperature below $16 \mathrm{~K}$. The helium then flows through tubes which are thermally connected to the items to be cooled.

The three remaining cooling loops are optimized to operate in a cryogenic steady-state mode, as shown in Figure 3. Each of the three loops have two cryocoolers. These loops operate at about $1.0 \mathrm{~g} / \mathrm{s}$ and $1.4 \mathrm{MPa}(200 \mathrm{psi})$. One loop is used to cool the cryostat base, one for the cryostat dome, and one for the equipment inside the cryostat. These loops each include three additional heat exchangers, $\mathrm{HX} 1, \mathrm{HX} 2$ and $\mathrm{HX} 3$, to maximize steady-state performance. The cooling module is also designed to raise the internal temperature of the cryostat to $473 \mathrm{~K}$ to help remove tritium that has been adsorbed by the inner wall.

\section{Thermal Analysis}

A thermal analysis was performed to evaluate the transient and steady-state performance of the fill/transfer station cryostat and cooling module. The thermal analysis was performed using both hand calculations and the General Atomics' two-dimensional finite difference code TAC2D. This code has been used for many years and has been validated in General Atomics' helium gas cooled reactor programs.

The TAC2D 3 model of the cryostat is axisymmetric and includes both the cryostat dome, base, and internal components and the cooling module. FORTRAN subroutines added to the code include cryocooler performance maps, temperature dependent material properties, liquid nitrogen boiling heat transfer, pressure drop along the flow loops, and heat exchangers characteristics. Parametric studies were also performed to examine the sensitivity of the system to cryocooler performance, mass and heat load variations.

The TAC2D analysis, verified by hand calculations, gave the total steady-state heat input to the $16 \mathrm{~K}$ wall as $26 \mathrm{~W}$. This heat load could be handled by two Sumitomo SRD$210 \mathrm{~W}$ cryocoolers, however, for operational reasons five separate flow loops are required. In addition, the customer requested redundancy in the three steady state flow loops bringing the total number of cryocoolers to eight.

The transient thermal analysis was also performed by TAC2D. The analysis gives the cooldown time to $16 \mathrm{~K}$ with eight cryocoolers as 10 hours. The stresses during this transient are all within allowables. 


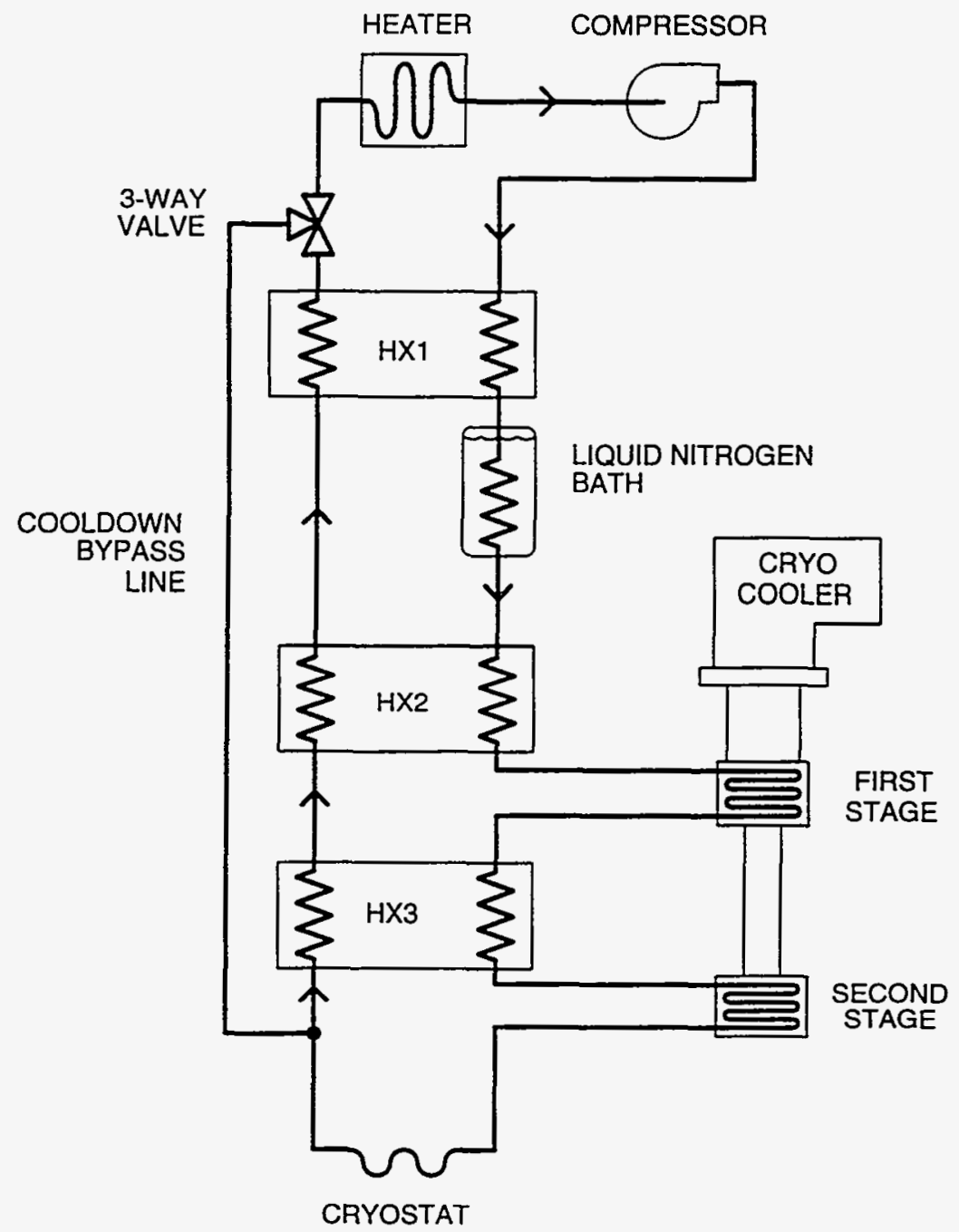

Figure 3. Schematic of steady-state flow loops (one of three).

\section{Stress Analysis}

The cryostat was designed and analyzed to the intent of the ASME Pressure Vessel Code. The stress analysis was performed using both hand calculations and the finite-element code ANSYS. The highest stressed region is the cryostat mouth, where the base and dome mate. This region is designed to be similar to a bayonet fitting. To minimize the heat leak, the two pieces must fit together with little clearance and must have minimum wall thickness. Using $1.50 \mathrm{~mm}(0.060 \mathrm{in}$.) thick 316 stainless steel for the walls satisfied both the structural and thermal constraints. However, to satisfy the buckling criteria, two stiffening rings were added to both the base and the dome.

The design is complicated by the fact that there are three independent vacuum spaces. In a fault condition, one of these spaces may be pressurized by a leak in a helium cooling loop or a liquid nitrogen tank. Evaluating all credible failure modes, gives large ranges of minimum to maximum stresses. This problem was solved by using very sensitive, $7 \mathrm{kPa}$ (1 psig), pressure relief valves on each vacuum space. 


\section{FILL AND TRANSFER EQUIPMENT DESIGN}

In addition to the cryostat, the fill/transfer station includes components which actually fill the targets with DT and to transfer them to the moving cryostat. The design of this equipment is challenging since they must operate in environments which include cryogenic temperatures, high pressures, tritium, and with extreme mechanical precision.

\section{Permeation Cell}

The permeation cell is located inside the cryostat inner volume. Although the cryostat interior walls remain cold, the permeation cell temperature is varied from $473 \mathrm{~K}$ to cryogenic temperatures. During target fill, the permeation cell is warm to allow the DT to permeate through the plastic target wall. Target fill is normally performed at room temperature, however increased permeation rates may be obtained at temperatures up to $473 \mathrm{~K}$. Once the desired pressure is reached, up to $152 \mathrm{MPa}(1500 \mathrm{~atm})$, the permeation cell is cooled to trap the solid DT inside the target.

The permeation cell is manufactured from A286, a precipitation-hardened high strength stainless steel alloy. To minimize thermal gradients, a copper sleeve is brazed to the cell wall. Electric heaters attached to this sleeve maintain the cell temperature during target fill. To cool the cell, helium gas is flowed through tubes attached to the outside of the permeation cell. This helium gas is cooled by liquid nitrogen and a cryocooler in the cooling module.

After the targets are inserted, the permeation cell must be sealed to allow it to be pressurized. This is accomplished by means of a breech lock and a pneumatic actuator built into the cell. The actual pressure seal consists of mating sixty degree cones, similar in design to high pressure tube fittings.

\section{Inserter and Target Manipulator}

These devices are used to manipulate the targets while they are at cryogenic temperatures. They are vacuum manipulators which consist of precision motion stages and bellows feedthroughs. Each axis of motion is driven by a stepper motor and controlled by a motion controller. The cold portion of these devices are actively cooled and are designed to minimize heat transfer.

The inserter is used to insert the targets into the permeation cell. It consists of a vertical thin-walled tube whose lower end is connected to an axial and rotary motion vacuum manipulator. Between the manipulator and the cryostat is a vacuum lock and a gate valve used to manually load the targets. In operation, the inserter raises the targets up into the cryostat and rotates sixty degrees to close the breech lock.

The target manipulator moves individual targets between the permeation cell and the moving cryostat. The movements are performed by a $x-y-z$ and rotary vacuum manipulator. The portion of the target manipulator located inside the cryostat consists of a thin-walled stainless steel tube extending up from the manipulator. Attached to the tube is a horizontal arm with a end effector on the far end. This end effector is designed to pick up an individual target and place it on the moving cryostat.

\section{Moving Cryostat Port}

The moving cryostat is the device which transports the target to the center of the OMEGA target chamber. It interfaces with the fill/transfer station cryostat at the moving cryostat port. This port includes equipment to remotely remove the thermal shield from the moving cryostat and cool it down to $16 \mathrm{~K}$. The thermal shield is lifted through the use of a ball screw driven linear stage which operates at cryogenic temperatures. Also included is a mechanism which precisely aligns the moving cryostat with the target manipulator during the target transfer. 


\section{Closed Circuit Television System}

The closed circuit television system allows the operator to confirm the position of all of the components inside the cryostat. It consists of one fiberscope and two borescopes. The fiberscope is attached to the arm of the target manipulator and travels with it. There is one borescope near the inserter to confirm that the target manipulator has picked up the target. The second borescope is near the moving cryostat port to confirm that the target manipulator has successfully dropped off the target. The borescopes will be oriented at right angles to the fiberscope to give the operator orthogonal views.

\section{Instrumentation and Control}

The instrumentation will consist of temperature, pressure, strain, tritium detection and alarm, and position sensors. All of the instrumentation will be interfaced into a local controller. This controller will be used to control the temperature and vacuum of the cryostat and to coordinate the motion of the vacuum manipulators.

\section{PROTOTYPE TESTING}

General Atomics has demonstrated the filling, cooling and transporting of targets using prototypical equipment. ${ }^{2}$ We have routinely filled $1 \mathrm{~mm}$ diameter mounted spheres with wall thickness as small as $3 \mu \mathrm{m}$ to the nominal fill pressure of $111 \mathrm{MPa}(1100 \mathrm{~atm})$ with deuterium. These targets were then cooled to $18 \mathrm{~K}$ to condense the fuel and transported outside of the cryostat.

The prototype cryostat however, was not designed for use with tritium. For example, indium o-rings were used to seal all flanges which see cryogenic temperatures. It would be nearly impossible, however, to handle indium wire through heavy gloves.

Other key pieces of equipment have also been demonstrated. A full scale permeation cell has demonstrated operation at both $152 \mathrm{MPa}(1500 \mathrm{~atm})$ and at $16 \mathrm{~K}$. A borescope has also been operated at cryogenic temperatures.

\section{STATUS}

The fill/transfer station design is complete and fabrication drawings are currently underway. Purchase orders for key long lead items have been placed including the cryocoolers with Sumitomo, the cryostat with Ability Engineering Technology, and the target manipulator with Thermionics NW. The system will be assembled and operated with deuterium at General Atomics and then shipped to the University of Rochester for DT testing. The system is scheduled to be operational by summer 1999.

\section{ACKNOWLEDGMENT}

The authors wish to acknowledge the dedicated and talented team which developed the design of the Fill / Transfer Station. Work supported by the U.S. Department of Energy under Contract No. DE-AC03-95SF20732.

\section{REFERENCES}

1. N.B. Alexander et al., The Cryogenic target handling system for the OMEGA laser, Proc. of the 16th IAEA Fusion Energy Conf., Montreal, Canada 1996 (International Atomic Energy Agency, Vienna, to be published).

2. G. E. Besenbruch et al, Testing of the cryogenic target handling system for the OMEGA laser, Proc. of the 19th Symposium on Fusion Technology, PF52 (1996).

3. R.H. Boonstra et al, TAC2D a general purpose two-dimensional heat transfer computer code - user's manual, General Atomics Report GA-A14032 (1976). 